\title{
Systemic Morphine Suppresses Noxious Stimulus-Evoked Fos Protein-like Immunoreactivity in the Rat Spinal Cord
}

\author{
R. W. Presley,' D. Menétrey, ${ }^{4}$ J. D. Levine, ${ }^{3}$ and A. I. Basbaum ${ }^{2}$ \\ Departments of ${ }^{1}$ Anesthesia, ${ }^{2}$ Anatomy and Physiology, and ${ }^{3}$ Medicine, University of California San Francisco, San \\ Francisco CA 94143, and ${ }^{4}$ NNSERM, U-161, 75014, Paris, France
}

Previous experiments have shown that noxious stimulation increases expression of the c-fos proto-oncogene in subpopulations of spinal cord neurons. c-fos expression was assessed by immunostaining for Fos, the nuclear phosphoprotein product of the $c$-fos gene. In this study, we examined the effect of systemic morphine on Fos-like immunoreactivity (FLI) evoked in the formalin test, a widely used model of persistent pain. Awake rats received a subcutaneous $150 \mu \mathrm{l}$ injection of $5 \%$ formalin into the plantar aspect of the right hindpaw. The pattern of nuclear FLI was consistent with the known nociceptive primary afferent input from the hindpaw. Dense labeling was recorded in the superficial dorsal horn (laminae $\mathrm{I}$ and $\mathrm{II}_{\mathrm{o}}$ ) and in the neck of the dorsal horn (laminae $V$ and $V I$ ), areas that contain large populations of nociceptive neurons. Sparse labeling was noted in lamina $I_{1}$ and in the nucleus proprius (laminae III and IV), generally considered to be nonnociceptive areas of the cord. Fos immunoreactivity was also evoked in the ventromedial gray, including laminae VII, VIII, and $X$. There was no labeling in lamina IX of the ventral horn.

Since FLI was time dependent and distributed over several spinal segments, we focused our analysis where maximal staining was found (L3-L5) and at the earliest time point of the peak Fos immunoreactivity $(2 \mathrm{hr})$. Twenty minutes prior to the formalin injection, the rats received morphine (1.0, 2.5, 5.0 , or $10 \mathrm{mg} / \mathbf{k g}$, s.c.) or saline vehicle. Two hours later, the rats were killed, their spinal cords removed, and $50 \mu \mathrm{m}$ transverse sections of the lumbar enlargement were immunostained with a rabbit polyclonal antiserum directed against Fos. Prior treatment with morphine sulfate profoundly suppressed formalin-evoked FLI in a dose-dependent and naloxone-reversible manner. The dose-response relationship of morphine-induced suppression of FLI varied in different laminae. To quantify the effect of morphine on FLI, labeled neurons in sections taken from the L4/5 level of each rat were plotted with a camera lucida and counted. Staining in the neck of the dorsal horn (laminae $V$ and $V I$ ) and in more

\footnotetext{
Received May 30, 1989; revised July 24, 1989; accepted July 26, 1989.

We wish to thank Ms. Allison Gannon and Ms. Simona Ikeda for expert technical and photographic assistance, and also Mme. Annie Menétrey for the preparation of graphics. We also thank Dr. Terence Coderre for assistance with statistical analyses. This work was supported by PHS grants NS14627, NS21445, and AM32634. R.W.P. was supported in part by Pain Research Training Program, NS07265. D.M. was supported by the Centre National de la Recherche Scientifique, France and a fellowship from NATO. This work was alsu partially funded by a generous personal donation from Dr. Thomas Farrell, Rancho Mirage, CA Correspondence should be addressed to Allan I. Basbaum, Department of Anatomy, Box 0452, University of California San Francisco, San Francisco, CA 94143. Copyright (C) 1990 Society for Neuroscience $0270-6474 / 90 / 010323-13 \$ 02.00 / 0$
}

ventral laminae VII, VIII, and $X$, was profoundly suppressed by doses of morphine which also suppress formalin-evoked behavior. Although the labeling was also significantly reduced in laminae I and II, at the highest doses of morphine there was substantial residual labeling in the superficial dorsal horn. These data indicate that analgesia from systemic opiates involves differential regulation of nociceptive processing in subpopulations of spinal nociceptive neurons.

The $c$-fos proto-oncogene is the mammalian homolog of the $v$-fos oncogene found in 2 murine osteogenic sarcoma viruses; $c$-fos encodes a nuclear phosphoprotein, Fos, that binds to DNA (Sambucetti and Curran, 1986). It has been proposed that the Fos protein functions as a nuclear "third messenger" molecule that couples short-term extracellular signals to long-term alteration in cell function, by regulating the expression of specific target genes (Curran and Morgan, 1985). Neuronal expression of the $c$-fos gene has been induced in the nervous system by nerve growth factor, cholinergic neurotransmitters, and by second messengers, such as $\mathrm{Ca}^{2+}$ and cAMP (Curran and Morgan, 1985; Greenberg et al., 1986; Morgan and Curran, 1986). Histochcmical studies in the rat CNS suggest that expression of the c-fos proto-oncogene, as measured by Fos protein immunocytochemistry, is a useful marker of neuronal activity that can be used to map functionally related neural pathways. With regard to sensory systems, Hunt et al. (1987) reported that both noxious and nonnoxious peripheral stimulation evokes $c$-fos expression in spinal cord neurons, and that the laminar distribution of these neurons is related to the nature of the sensory stimulus. Noxious thermal, chemical, and mechanical cutaneous stimuli evoked Fos-like immunoreactivity (FLI) in nuclei of neurons located predominantly in laminae $\mathrm{I}, \mathrm{I}_{\mathrm{o}}$, and $\mathrm{V}$, where the majority of nociceptive primary afferents terminate (Light and Perl, 1979; Swett and Woolf, 1985; Sugiura et al., 1987), and where dorsal horn nociceptive neurons predominate (for review, see Besson and Chaouch, 1987). It was later shown that a subpopulation of noxious stimulus-evoked Fos-immunoreactive neurons are at the origin of ascending spinal pathways that have been implicated in the rostral transmission of nociceptive messages (Menétrey et al., 1989). In the present study, we address the question of how systemic administration of morphine, the prototypical narcotic analgesic, affects noxious stimulus-evoked FLI in rat spinal neurons.

Since FLI is best evoked in the rat CNS by prolonged, repetitive, or continuous stimulation, we have chosen to study the Fos response in a standard model of "tonic" pain, the socalled formalin test. The tonic noxious stimulus, subcutaneous formalin injection into the paw, is presumed to better model 
clinical pain, which is continuous in nature, than do acute, phasic tests of nociception (Dennis and Melzack, 1979). This stimulus produces a stereotypical behavioral syndrome in rats, cats (Dubuisson and Dennis, 1977), and monkeys (Alreja et al., 1984) that is thought to be indicative of pain. Rats protect and may lick the injected paw, but do not vocalize. The behavior is suppressed by nonsteroidal antiinflammatory drugs (Hunskaar et al., 1986; Drower et al., 1987), systemically administered opiate analgesics, including morphine (Dubuisson and Dennis, 1977; Dennis and Melzack, 1979, 1980; Abbott et al., 1982; Drower et al., 1987), intracerebroventricular injection of opioid agonists (Calcagnetti et al., 1988), and electrical stimulation of brain-stem sites that produce analgesia in other nociceptive tests (Dubuisson and Dennis, 1977). Formalin injection induces longlasting, opiate-sensitive, excitation of dorsal horn nociceptive ncurons, the time course of which correlates with the formalin behavioral syndrome (Dickenson and Sullivan, 1987a, b).

\section{Materials and Methods}

All cxpcriments werc performed on male Sprague-Dawley rats (240$340 \mathrm{gm}$; Bantin and Kingman, Fremont, CA), with the approval of the UCSF Committee on Animal Research. Preliminary data in our laboratory (Presley et al., unpublished observations) demonstrated that commonly used anesthetics (barbiturate, fluothane, and ketamine) significantly restrict the spinal distribution of noxious stimulus-evoked FLI. Thus, the complete pattern of noxious stimulus evoked $c$-fos expression would be masked under anesthetic conditions. Furthermore, since we wished to evaluate the mechanisms through which morphine exerts its analgesic effect, it was important to perform the experiments under conditions in which the behavior of the animals could be monitored. For these reasons, the experiments were performed in awake, freely moving rats. We injected the plantar surface of the right hindpaw with $150 \mu \mathrm{l}$ of $5 \%$ formalin subcutaneously and then examined the time coursc of formalin-cvoked $c$-fos expression; groups of rats were killed at $1,2,4,8$, and $16 \mathrm{hr}$ postinjection. Thereafter, we focused our studies on rats killed $2 \mathrm{hr}$ postinjection because this was the earliest time of peak Fos-immunoreactive staining.

The treatment groups consisted of rats that received subcutaneous morphine sulfate (injectable solution, $15 \mathrm{mg} / \mathrm{ml}$, Elkins-Sinn, Cherry Hill, NJ) diluted in normal saline. Rats in the different treatment groups received morphine in doses of either $1.0 \mathrm{mg} / \mathrm{kg}(n=4), 2.5 \mathrm{mg} / \mathrm{kg}(n$ $=3), 5.0 \mathrm{mg} / \mathrm{kg}(n=3)$, or $10 \mathrm{mg} / \mathrm{kg}(n=4), 20 \mathrm{~min}$ prior to the injection of formalin. Control rats $(n=8)$ received an equal volume of saline vehicle. We also attempted to reverse the effect of morphine (10 $\mathrm{mg} / \mathrm{kg}$, s.c.) by the combined administration of the opiate-receptor antagonist, naloxone hydrochloride (Lyphomed, Melrose Park, IL), 2.0 $\mathrm{mg} / \mathrm{kg}$, i.p. $(n=3)$. Naloxone was administered $5 \mathrm{~min}$ prior to the morphinc injection; the dose of naloxone was repeated every $30 \mathrm{~min}$ up to the time of sacrifice, to compensate for the short half-life of naloxone as compared with morphine.

Two hours after the formalin injection, the rats were deeply anesthetized with pentobarbital $(60 \mathrm{mg} / \mathrm{kg}$, i.p.) followed immediately by intracardiac perfusion with $250 \mathrm{ml} 0.05$ м PBS followed by $500 \mathrm{ml} 4 \%$ paraformaldehyde fixative in $0.1 \mathrm{M}$ phosphate buffer (PB). After perfusion, the lumbar spinal cord was removed and postfixed in $4 \%$ paraformaldehyde for 4-6 hr and then cryoprotected overnight in 30\% sucrose in $0.1 \mathrm{M}$ PB. Fifty micron frozen sections, cut in the transverse plane, were taken from all lumbar levels and collected in $0.05 \mathrm{M}$ PBS for immunocytochemical analysis. The sections were then immunostained for Fos protein by the avidin-biotin-peroxidase (ABC) method of Hsu et al. (1981). The tissue sections were washed with a solution of 0.05 $M$ PBS with $1 \%$ normal goat scrum and $0.3 \%$ Triton- $X$ and then incubated for $1 \mathrm{hr}$ at room temperature in a blocking solution of $3 \%$ normal goat serum in $0.05 \mathrm{M}$ PBS with $0.3 \%$ Triton-X. The blocking solution was aspirated from the tissue, and the sections were incubated overnight at $4^{\circ} \mathrm{C}$ in the primary antiserum directed against the Fos protein (described below). The sections were then incubated in biotinylated goat anti-rabbit IgG and avidin-biotin-peroxidase complex (Vector Labs, Burlingame, $\mathrm{CA}$ ). The reaction product was visualized with $0.01 \%$ hydrogen peroxide and $0.05 \%$ diaminobenzidine (DAB) as the chromogen. In every case, tissue from control and treated animals was reacted simultaneously, for the same period of time and with the same reagents.

The primary antiserum used in all reactions was a rabbit polyclonal antiserum (kindly provided by Dr. Dennis Slamon of the Departments of Haematology and Oncology at UCLA) directed against the protein product of an in vitro translated $c$-fos gene. The antiserum was routinely preabsorbed against acetone-dried rat liver powder overnight to reduce nonspecific background staining and diluted 1:5000 prior to use. The complete Fos protein was not available in sufficient quantities to permit absorption controls for the rabbit polyclonal Fos antiserum. However, we have performed similar experiments using a murine monoclonal antiserum that was directed against a synthetic peptide which corresponded to the N-terminal (residues 4-17) of the Fos protein (Microbiological Associates Inc., Bethesda, MD) and also diluted 1:5000. The pattern of staining and the overall distribution of labeled neurons with the monoclonal and polyclonal antisera were comparable. Staining with the N-terminal directed monoclonal antiserum was completely abolished when it was preabsorbed with the $\mathrm{N}$-terminal peptide fragment. Omission of the Fos antiserum from the immunostaining protocol likewise completely abolished labeling. Although the staining patterns of the 2 antisera tested did not differ significantly, we used the rabbit polyclonal antiserum in our experiments because it always produced more intense immunoreactivity.

After the immunostaining procedure, tissue sections were mounted on slides, air-dried, and coverslipped. The sections were first examined under dark-field illumination to determine gray matter landmarks and segmental level (Molander et al., 1984) and were then sketched with a camera lucida attachment. The sections were then examined under brightfield illumination and neurons with stained nuclei ipsilateral to the injected paw were plotted with a camera lucida attachment. A neuron was considered to be labeled only if the nucleus showed the characteristic brown staining of oxidized $\mathrm{DAB}$, and was distinct from background at magnifications of $4 \times, 10 \times$, and $20 \times$. By terminating the immunostaining reaction just at the point that light background staining was evident, we were able to easily distinguish Fos-immunoreactive neurons from background.

We quantitated the effect of morphine on FLI by counting all the labeled cells plotted on 3 sections taken from the L4/5 level of each rat. The average number of plotted cells in those 3 sections was recorded as the number of Fos-immunoreactive neurons in that rat. For each rat, the total of number of cells was recorded, as well as the subtotal in specific laminar regions of the ipsilateral spinal gray matter, as follows (see Fig. 9); superficial dorsal horn (laminae I and II), nucleus proprius (laminae III and IV), neck of the dorsal horn (laminae V and VI), and the ventral gray (laminae VII, VIII, IX, and X). The effects of different morphine doses on total numbers of Fos-immunoreactive neurons were compared using 1-way analysis of variance and Dunnett's $t$ test for multiple comparisons with control. The numbers of labeled cells were also compareci using 2-way analysis of variance for dose and region, and again Dunnett's $t$ test was used for post hoc comparisons. Although we were not able to quantify the density of labeling in individual neurons, we also report our impressions of changes in staining intensity that occurred after morpinine treatment. Throughout the data-collection phase, the investigators were blind to treatment and time of postinjection sacrifice.

\section{Results}

\section{Fos expression in the formalin test General features}

Consistent with the known nuclear location of the Fos protein (Curran, 1984), Fos-immunoreactive neurons were easily recognized by their diffusely stained nuclei and unlabeled nucleoli. Almost no cytoplasmic staining was found; scant, filamentous staining of the cytoplasm in the ependymal cells lining the central canal was typically noted, and cytoplasmic staining was sometimes present bilaterally in the lateral spinal nucleus of the dorsolateral funiculus (Fig. $4 C$ ). Rarely, we noted cytoplasmic staining of cells in the substantia gelatinosa and nucleus proprius, occasionally associated with immunostained dendrites and terminals. In every case, this presumed cross-reactive staining was easily distinguished from the diffuse, nuclear FLI. 


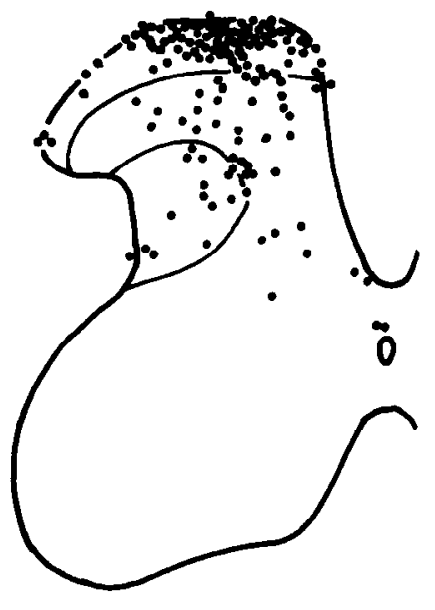

1 hour

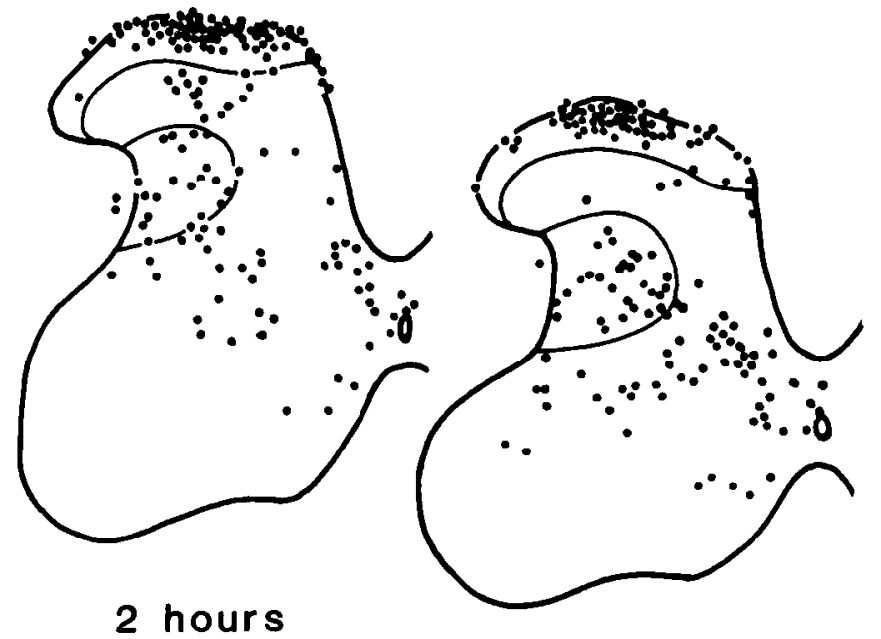

4 hours

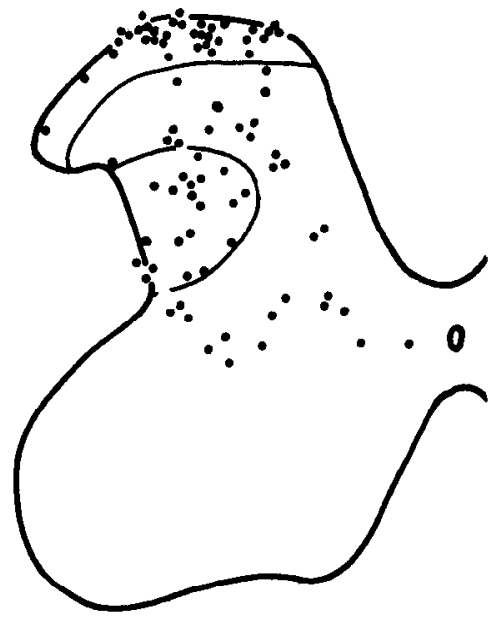

8 hours

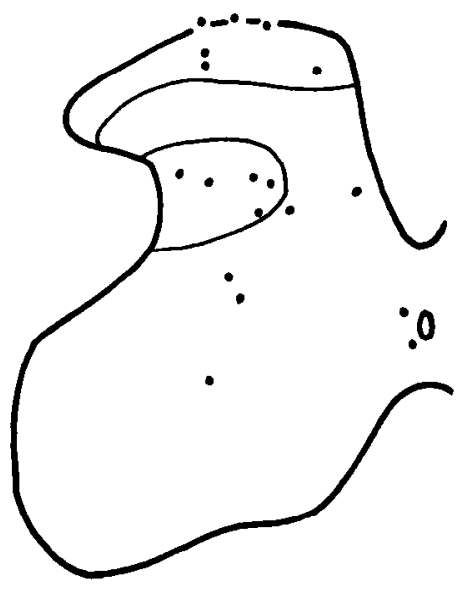

16 hours
Figure 1. Camera lucida drawings taken from the L4-5 level of rats killed at various times after formalin injection. Maximal Fos immunoreactivity is present by $2-4 \mathrm{hr}$ postinjection and then it slowly disappears. Staining is barely above control by $16 \mathrm{hr}$ postinjection. Dense superficial staining appears by 1 $\mathrm{hr}$, but ventral staining requires at least $2 \mathrm{hr}$ to become evident.
The basal level of FLI in spinal neurons of unstimulated rats (no formalin injection) was extremely low; less than 5 very lightly stained nuclei were present per $50 \mu \mathrm{m}$ section. The few labeled cells that were detected in sections from unstimulated animals were primarily located in laminae III and IV, bilaterally. In contrast, injection of formalin into the plantar hindpaw evoked dramatic FLI in the gray matter of the lumbar enlargement (Figs. $2,3 A$ ). The grcatest numbers of labeled neurons evoked by formalin were noted at the L3-L5 levels, corresponding to the segmental innervation of the rat plantar hindpaw (Molander and Grant, 1985; Swett and Woolf, 1985). With the exception of lamina VIII, which sometimes contained labeled neurons bilaterally (Figs. $3 D, 5 D$ ), FLI was largely confined to the side of the cord ipsilateral to the injured paw. For this reason, the camera lucida drawings in Figures 1, 2, 6, and 7 only illustrate the spinal gray matter ipsilateral to the injured paw.

\section{Time course and spatial distribution}

Fos-like immunoreactivity evoked by formalin injection was time dependent (Fig. 1). By $1 \mathrm{hr}$ postinjection, dense Fos labeling was present in the superficial dorsal horn (laminae $\mathrm{I}$ and $\mathrm{II}_{\mathrm{o}}$ ). The staining was already near peak levels in this area, both in terms of numbers of positive cells and in the intensity of their staining. Laminae III, IV, and the lateral neck of the dorsal horn (lamina V) contained moderate numbers of labeled neurons; a few lightly labeled nuclei were present in laminae VI, VII, and $\mathrm{X}$. At 2-4 hr postinjection, we observed the most extensive Fos labcling; intense staining of the superficial dorsal horn, comparable to that observed at $1 \mathrm{hr}$, persisted. The most striking difference at $2 \mathrm{hr}$ was the larger number of labeled neurons that appeared in the deep dorsal horn (lamina V and VI) and in the ventral gray (laminae VII, VIII, and X). Labeled neurons in lamina VIII were sometimes present bilaterally (Figs. 3, $A, D$; $5 D$ ). In general, the neurons in the superficial dorsal horn and in the neck of the dorsal horn were more darkly stained, as compared with neurons in the nucleus proprius and ventromedial gray. Finally, labeled neurons were sparse in lamina II $_{i}$ (Fig. 4A), and almost none were found in Lamina IX (Fig. 3).

This pattern of staining persisted essentially unchanged through $4 \mathrm{hr}$ postinjection (Fig. 1). By $8 \mathrm{hr}$, the labeling in the superficial 
Figure 2. Camera lucida drawings showing the rostrocaudal distribution of Fos-immunoreactive neurons $2 \mathrm{hr}$ after formalin injection into the ipsilateral plantar hindpaw. The most intense immunoreactivity is noted at the L3-L5 segments, which receive the major afferents from the plantar hindpaw. Labeling in the superficial dorsal horn is predominantly restricted to the L3L5 segments, whereas labeling in the neck of the dorsal horn and ventromedial gray is present throughout the lumbar enlargement.

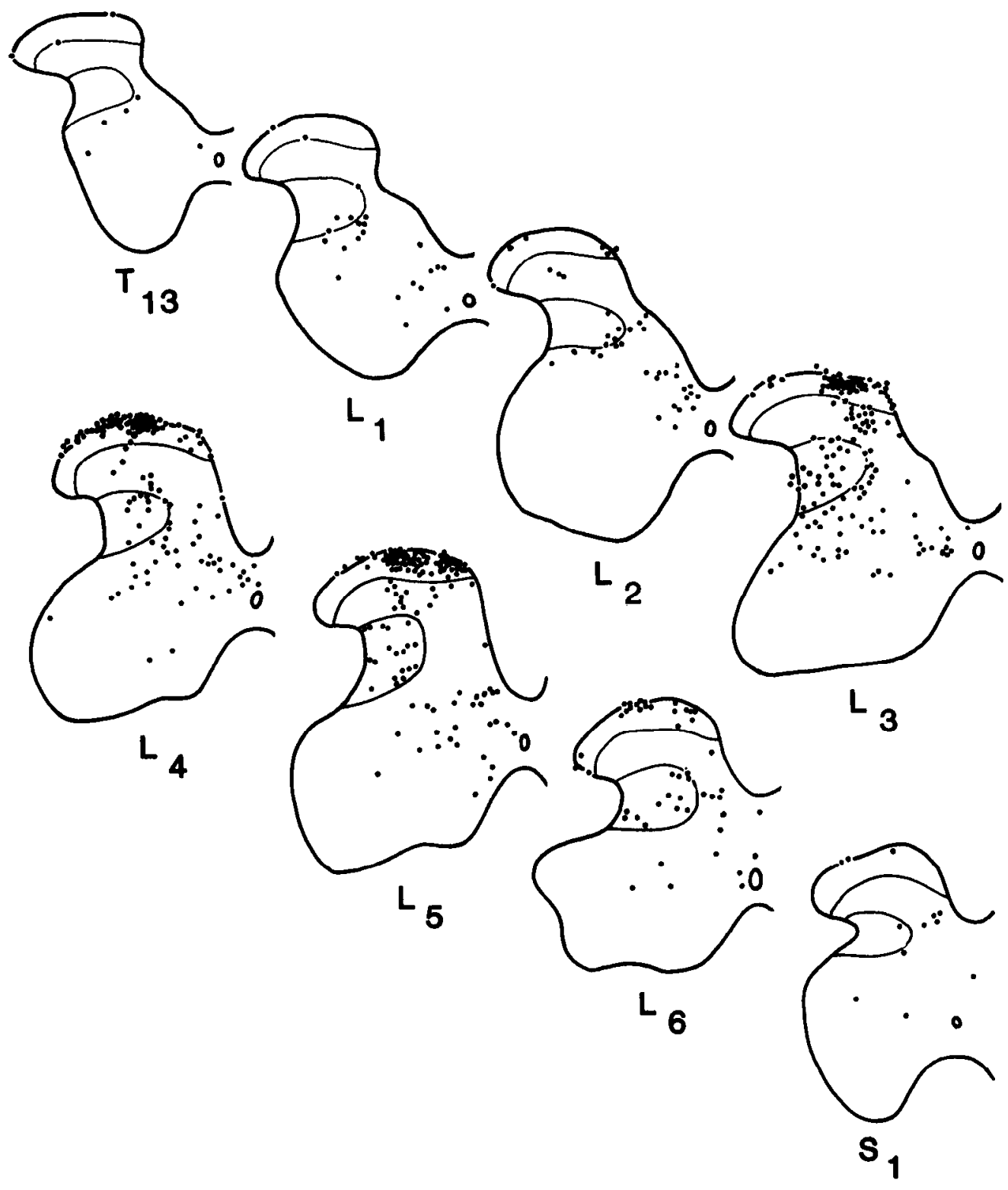

neck of the dorsal horn (laminae V, VI, and VII) was distributed rather uniformly across the medial-lateral extent of the gray matter.

The rostrocaudal distribution of formalin-evoked FLI was confined to the lumbar enlargement. The most intense staining was observed at levels L3-LS (Fig. 2). Rostral and caudal to L3-L5, the number of positive cells rapidly diminished. This was particularly true in the superficial dorsal horn (laminae I and $\mathrm{II}_{\mathrm{o}}$ ). Labeled neurons in laminae V, VI, VII, VIII, and $\mathrm{X}$ also declined at levels beyond L3-L5; however, they could still be detected up to 3 segments rostral and caudal to L3-L5. In light of these results, we focused our studies of the effects of morphine on FLI at the L3-L5 levels, $2 \mathrm{hr}$ postformalin injection, the earliest time of peak Fos immunoreactivity.

\section{Effect of morphine}

Control injections of morphine $(10 \mathrm{mg} / \mathrm{kg}$, s.c.) in unstimulated rats (i.e., no formalin injection) did not change the low basal level of FLI that is usually seen in the nucleus proprius. Control lamina I. The lateral substantia gelatinosa and nucleus proprius were almost devoid of labeled cells. By contrast, staining in the 

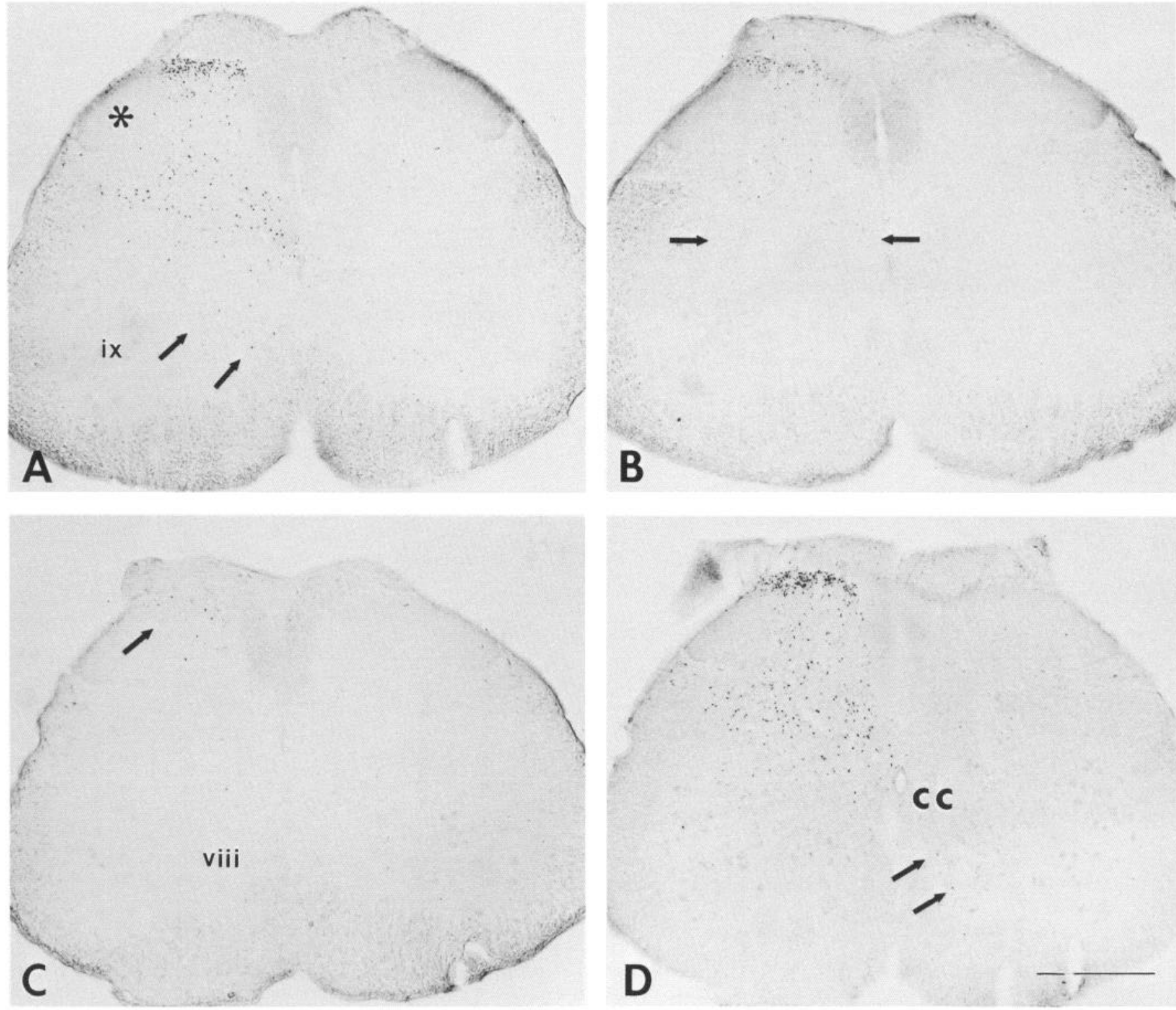

Figure 3. These photomicrographs illustrate the pattern of formalin-evoked Fos immunoreactivity in neurons from sections of the L4/5 spinal cord of untreated $(A)$, morphine-treated $(B, C)$, or morphine plus naloxone-treated $(D)$ rats. In control rats $(A)$, there is dense labeling in the superficial layers (laminae I and II) and in the neck of the dorsal horn, as well as in laminae VII and VIII of the ventral horn (arrows), ipsilateral to the noxious stimulus. There are no Fos-immunoreactive neurons in the motoneurons pools, lamina IX (ix). The densest labeling is in the medial part of the superficial dorsal horn; the lateral part (asterisk) does not receive primary afferent input from the plantar hindpaw. B, Pretreatment with morphine $(2.5 \mathrm{mg} / \mathrm{kg}$, s.c.) reduced the number of labeled cells in the dorsal horn and eliminated the staining of cells in laminae VII and VIII of the ventral horn (i.e., ventral to the arrows); the labeling in the superficial dorsal horn is still intense. $C$, Morphine (10 mg $/ \mathrm{kg}$, s.c.) almost completely blocked Fos-immunostaining; some lightly labeled cells, however, persisted in the superficial dorsal horn (arrow), $D$, Combined administration of naloxone $(2.0 \mathrm{mg} / \mathrm{kg}$, i.p.) completely reversed the morphine $(10 \mathrm{mg} / \mathrm{kg}$, s.c.) suppression of Fos-staining; bilateral staining was detected in lamina VIII (arrows). cc, Central canal. Scale bar, $500 \mu \mathrm{m}$.

injections of naloxone $(2.0 \mathrm{mg} / \mathrm{kg}$, i.p.) in unstimulated rats also had a minimal effect on basal Fos immunoreactivity; however, in distinction to morphine, after naloxone injection we detected a few $(<10)$ lightly labeled neurons scattered throughout the dorsal horn (laminae I-VII), bilaterally.

Morphine treatment markedly decreased FLI in all laminae and at all lumbar levels (Figs. 3-7). This effect of morphine was characterized by fewer labeled neurons, as well as by lighter staining of those neurons that were labeled (Figs. $3 C, 4 C$ ). It was most obvious on staining in the deeper layers of the dorsal horn, in laminae V and VI, and on staining in the ventral horn, in laminae VII, VIII, and X (Fig. 5). Staining was reduced in the superficial dorsal horn, laminae $\mathrm{I}$ and $\mathrm{II}_{\mathrm{o}}$, however many labeled cells were still present superficially, even after treatment with the highest dose of morphine $(10 \mathrm{mg} / \mathrm{kg})$. The staining of these residual cells was much less intense than in control sections (Figs. 3C, 4C).

The morphine effect was dose dependent. A comparison of the total numbers of Fos-immunoreactive neurons in the morphine-treated groups and controls revealed the following (Fig. 8): $91 \%$ of control for the $1.0 \mathrm{mg} / \mathrm{kg}$ group ( $p=\mathrm{NS}$ ), $47 \%$ of control for the $2.5 \mathrm{mg} / \mathrm{kg}$ group ( $p<0.05$ ), $33 \%$ of control for 


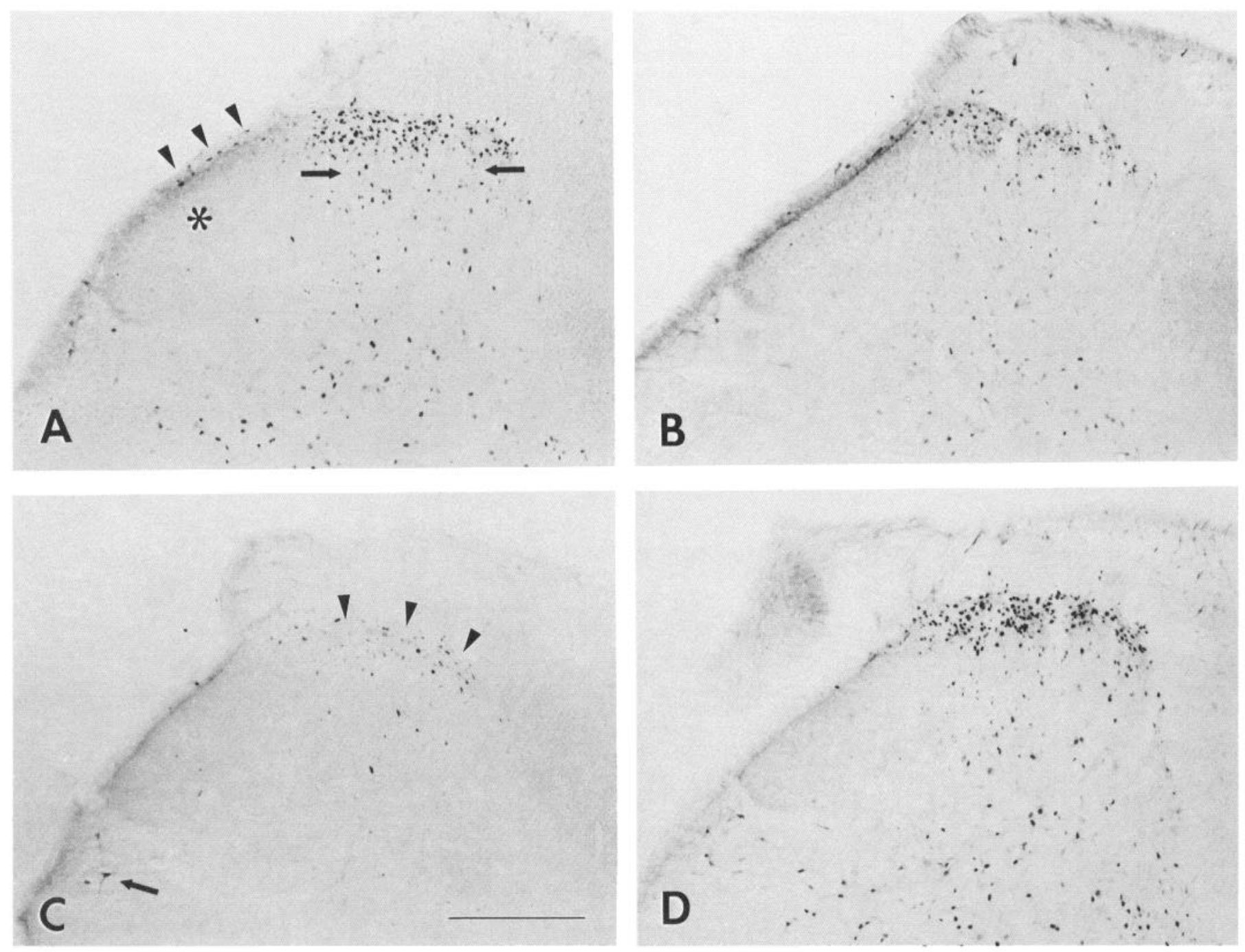

Figure 4. These higher-magnification photomicrographs of the sections from Figure 3 better illustrate the noxious stimulus-evoked labeling pattern. $A$, In the control, there is dense labeling in the medial part of laminae $\mathrm{I}$ and $\mathrm{II}_{\mathrm{o}}$ of the superficial dorsal horn. With the exception of some labeled neurons at the surface of the cord (arrowheads), there is almost no labeling in the lateral dorsal horn (asterisk) and very little in the inner part of the substantia gelatinosa $\left(\mathrm{II}_{\mathrm{i}}\right)$, which contains neurons that only respond to innocuous stimulation. $B, \mathrm{Morphine}(2.5 \mathrm{mg} / \mathrm{kg}, \mathrm{s.c}$.) produces a significant reduction in the number of labeled neurons. $C$. Morphine $(10 \mathrm{mg} / \mathrm{kg}$, s.c.) has a profound suppressive effect on the labeling of neurons; only lightly labeled cells remain in the superficial layers of the dorsal horn (arrowheads). The arrow points to cross-reacting cytoplasmic staining in neurons of the lateral spinal nucleus. $D$, Combined administration of naloxone $(2.0 \mathrm{mg} / \mathrm{kg}$, i.p.) blocks the effect of morphine (10 mg/kg, s.c.) and returns the staining pattern to that of the control. Scale bar, $100 \mu \mathrm{m}$.

the $5.0 \mathrm{mg} / \mathrm{kg}$ group $(p<0.01)$, and $21 \%$ of control for the 10 $\mathrm{mg} / \mathrm{kg}$ group $(p<0.01)$. One-way analysis of variance showed a statistically significant difference between doses $[F(5,19)=$ $11.7, p<0.001]$. Combined administration of naloxone $(2.0$ $\mathrm{mg} / \mathrm{kg})$ reversed the suppressive effect of morphine $(10 \mathrm{mg} / \mathrm{kg})$. The number of Fos-immunoreactive neurons in the naloxonetreated rats was not significantly different from control levels ( $p$ $=$ NS).

The effect of morphine was also region dependent (Figs. 911). Two-way analysis of variance showed a significant main effect of dose $[F(4,17)=15.7, p<0.001]$ and a significant main effect of region $[F(3,51)=155.9, p<0.001]$, as well as a significant dose $\times$ region interaction $[F(12,51)=7.0, p<0.001]$. This indicates that the dose-response relationship varied among the different regions. The superficial dorsal horn showed especially steep declines in the number of Fos-immunoreactive neu- rons. The decrease was statistically significant $(p<0.01)$ at 2.5 $\mathrm{mg} / \mathrm{kg}$ morphine and plateaued somewhat at higher doses. FLI in the neck of the dorsal horn showed a steep decline at $2.5 \mathrm{mg} /$ $\mathrm{kg}$. A further decrease was found at $5.0 \mathrm{mg} / \mathrm{kg}$, but no additional effect was observed at the dose of $10 \mathrm{mg} / \mathrm{kg}$. FLI in the ventral gray was also significantly reduced at a dose of $2.5 \mathrm{mg} / \mathrm{kg}(p<$ 0.05 ) and staining was almost abolished at the 5.0 and $10 \mathrm{mg} /$ $\mathrm{kg}$ doses $(p<0.01)$. In contrast, the dose-response curve for the nucleus proprius was relatively flat, and there was no statistically significant effect of any dose of morphine on the numbers of labeled cells in this area.

The differential effect of morphine on FLI in different laminar regions is best illustrated in Figure 11, in which the data are reported for each region that showed significant suppression as a percentage of its own control. The relative morphine effect is identical in the superficial dorsal horn and neck of the dorsal 


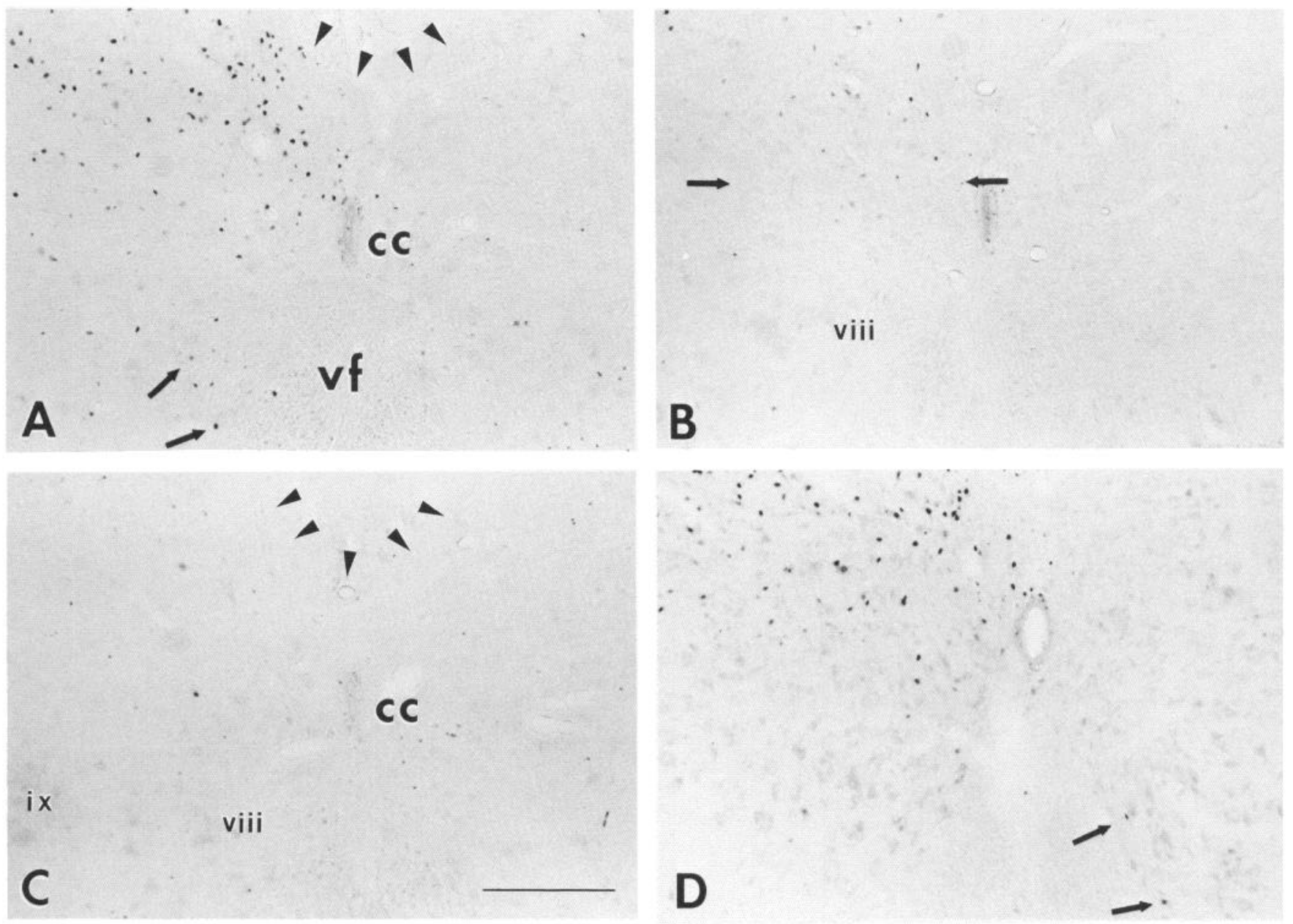

Figure 5. These photomicrographs illustrate the noxious stimulus-evoked labeling in the deep dorsal horn and ventromedial gray matter from the same sections shown in Figures 3 and 4 . $A$, In the control, there is dense labeling around the central canal $(c c)$, and there are many cells in lamina VIII (arrows). B, After morphine, $2.5 \mathrm{mg} / \mathrm{kg}$, labeling is profoundly suppressed in these areas (below arrows), but there is still significant labeling in the deep dorsal horn (above arrows). C, After $10 \mathrm{mg} / \mathrm{kg}$ morphine, labeling in the deep dorsal horn is also profoundly suppressed. $D$, Combined administration of naloxone $(2.0 \mathrm{mg} / \mathrm{kg}$, i.p.) with morphine $(10 \mathrm{mg} / \mathrm{kg}$, s.c.) returns labeling to control levels, including staining in contralateral lamina VIII (arrows). vf, Ventral funiculus; arrowheads, dorsal border of gray matter; viii, lamina VIII; ix, lamina IX. Scale bar, $200 \mu \mathrm{m}$.

horn after doses of $2.5 \mathrm{mg} / \mathrm{kg}$. At higher doses, the suppression in the superficial dorsal horn is always less than in the neck. As a consequence, FLI in both control and treated rats was always more pronounced in the superficial layers than in deeper areas of the spinal gray. The effect of morphine is also greatest on ventral FLI at all doses. Furthermore, morphine significantly reduced the rostrocaudal distribution of labeled neurons in a dose-dependent manner. This was primarily due to suppression of the more ventral cells, which, as noted above, are the cells that have the greatest rostrocaudal spread in saline controls. Doses of 2.5 and $5.0 \mathrm{mg} / \mathrm{kg}$ showed a reduction of the rostrocaudal distribution of labeled neurons; with $10 \mathrm{mg} / \mathrm{kg}$, FLI was not above baseline at segments rostral or caudal to the L3-5 levels (Fig. 7). Finally, although we were not able to quantitate the density of staining in individual neurons, it is our clear impression that the density of staining was substantially reduced in the Fos-immunoreactive neurons that remained after morphine treatment (Figs. $3 C, 4 C$ ). In contrast, naloxone treatment may have resulted in more intense immunoreactivity (Figs. $3 D$, $4 D)$.

\section{Discussion}

We have shown that a tonic noxious chemical stimulus, produced by subcutaneous formalin injection, can evoke expression of Fos protein-like immunoreactivity in spinal cord neurons of awake rats and that morphine suppresses the noxious stimulusevoked FLI in a dose-dependent manner; since the inhibitory effect of morphine was naloxone reversible, we conclude that the suppression of Fos expression was opiate receptor mediated. Importantly, previous experiments showed that there is a dosedependent increase in the $c$-fos message in response to excitatory cholinergic neurotransmitters in vitro and that specific pharmacologic antagonists abolished this response (Greenberg et al., 1986). Thus, the relative density of staining of spinal neurons in our preparations probably reflects their relative degree of neuronal activity in response to excitatory afferent input.

Our results support the use of Fos immunocytochemistry to map functionally related neural circuits in the CNS (Hunt et al., 1987; Sagar et al., 1988; Menétrey et al., 1989). The principle advantage of this technique in the study of nociception is that 
Figure 6. Camera lucida drawings of representative $\mathrm{L} 4 / 5$ sections showing a dose-related, naloxone-reversible inhibition of formalin-evoked FLI by morphine. The labeling in the ventral gray matter is profoundly suppressed by 2.5 $\mathrm{mg} / \mathrm{kg}$; at any given dose, the region with the most residual staining is the superficial dorsal horn.
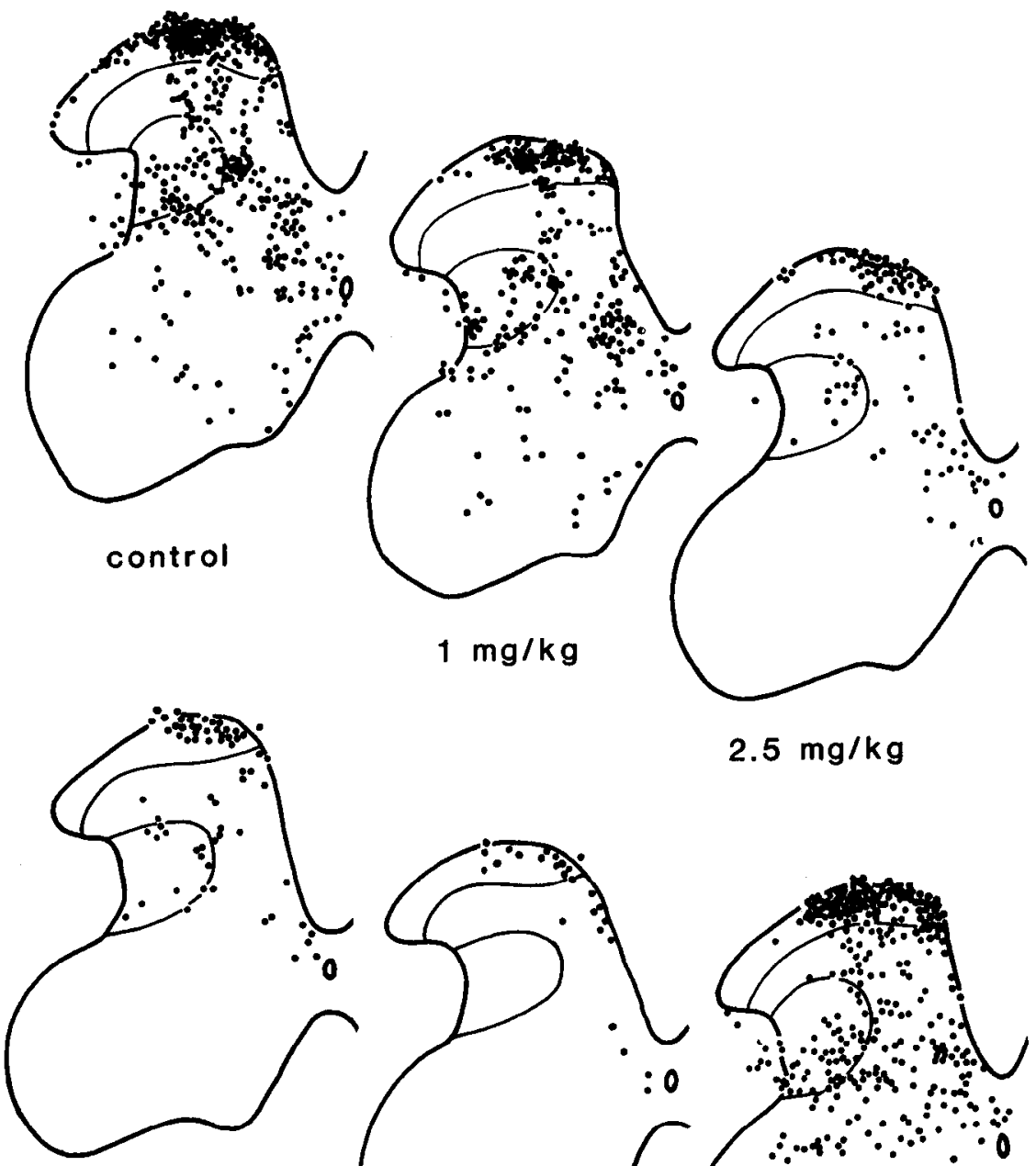

$5 \mathrm{mg} / \mathrm{kg}$
$2.5 \mathrm{mg} / \mathrm{kg}$

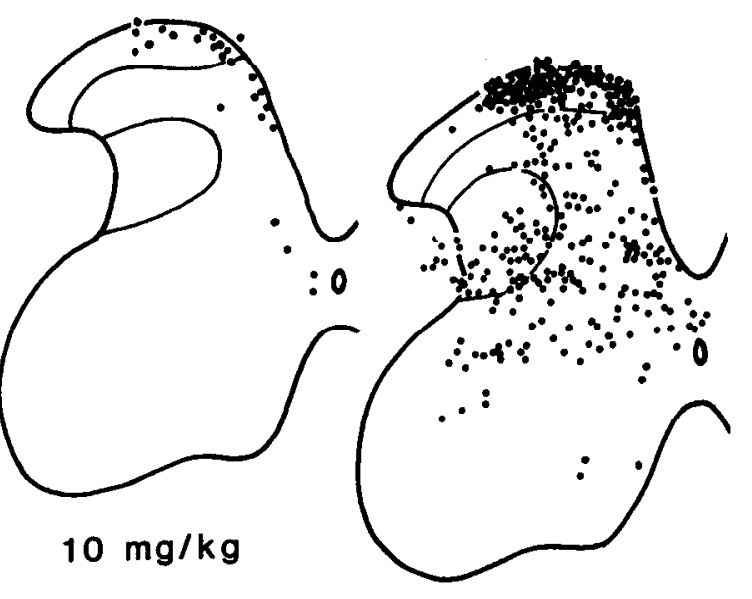

morphine $10 \mathrm{mg} / \mathrm{kg}$ naloxone $2 \mathrm{mg} / \mathrm{kg}$ it reveals large populations of presumed nociceptive neurons in individual animals, with resolution at the single-cell level. Although it is possible to quantitate noxious stimulus-evoked neural activity with the 2-deoxy-glucose method (Abram and Kostreva, 1986), that procedure does not have cellular resolution and is much more difficult to perform. The cytochrome oxidase method (Wong-Riley and Kageyama, 1986) has cellular resolution, but high baseline levels of cytochrome oxidase activity in the spinal cord would make it difficult to detect noxious stimulusevoked changes in enzyme activity. A particularly important advantage of monitoring $c$-fos expression for spinal cord studies is that FLI is very low in the spinal cords of unstimulated rats; thus, induction of FLI by noxious stimuli is readily detected. In fact, the absence of substantial basal FLI distinguishes the spinal cord from certain brain stem and forebrain areas, including the solitary nucleus, cerebral cortex, hippocampus, striatum, and cerebellum (Morgan et al., 1987; Sagar et al., 1988). The principle disadvantage of this technique is that it is difficult to quantitate; simply counting labeled nuclei does not adequately account for the wide variation of staining intensity among labeled neurons. We are presently evaluating a single cell densitometric approach to quantitate changes in staining intensity in individual cells.

Our results are consistent with electrophysiological studies that have demonstrated that populations of both nociceptivespecific and wide-dynamic-range nociceptive neurons are located predominantly in the superficial dorsal horn (laminae I and $\mathrm{II}_{\mathrm{o}}$ ), and in the neck of the dorsal horn (lamina $\mathrm{V}$ ) (reviewed by Besson and Chaouch, 1987). It is in these areas where we noted the earliest and most intense noxious stimulus-evoked Fos immunoreactivity. Consistent with previous studies showing that primary afferents that innervate the distal extremities terminate in the medial superficial dorsal horn and that input from the proximal extremities is represented more laterally, we found that Fos-immunoreactive neurons were concentrated in the medial part of the superficial dorsal horn (Light and Pcrl, 


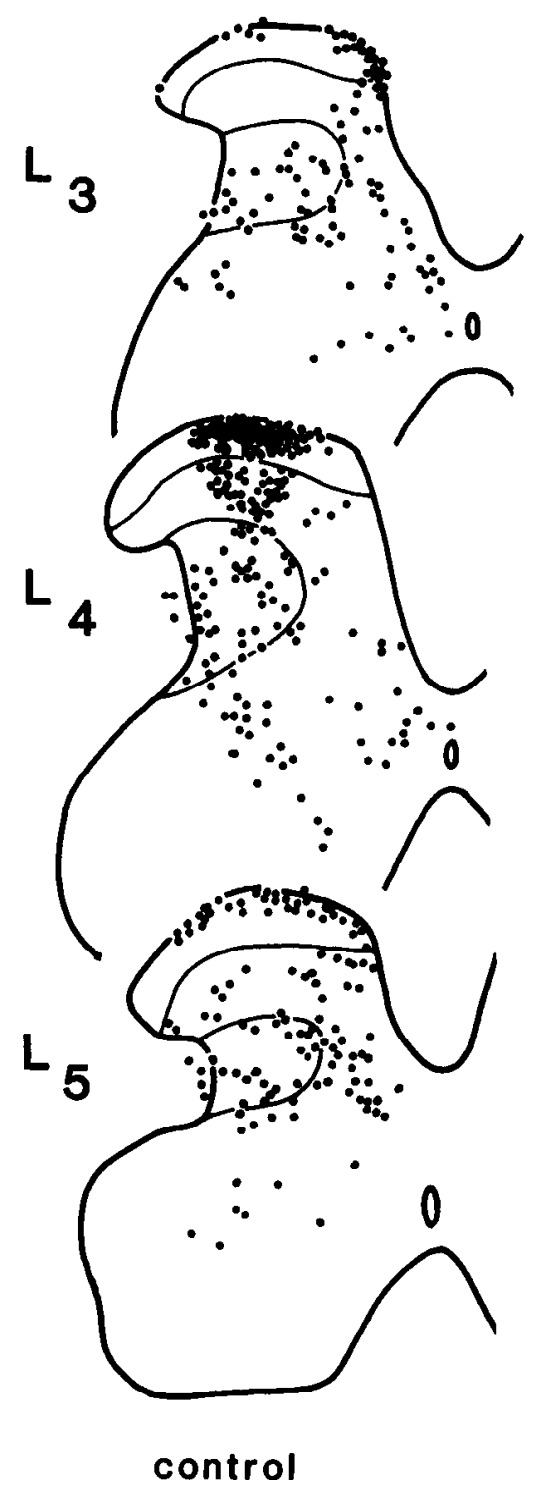

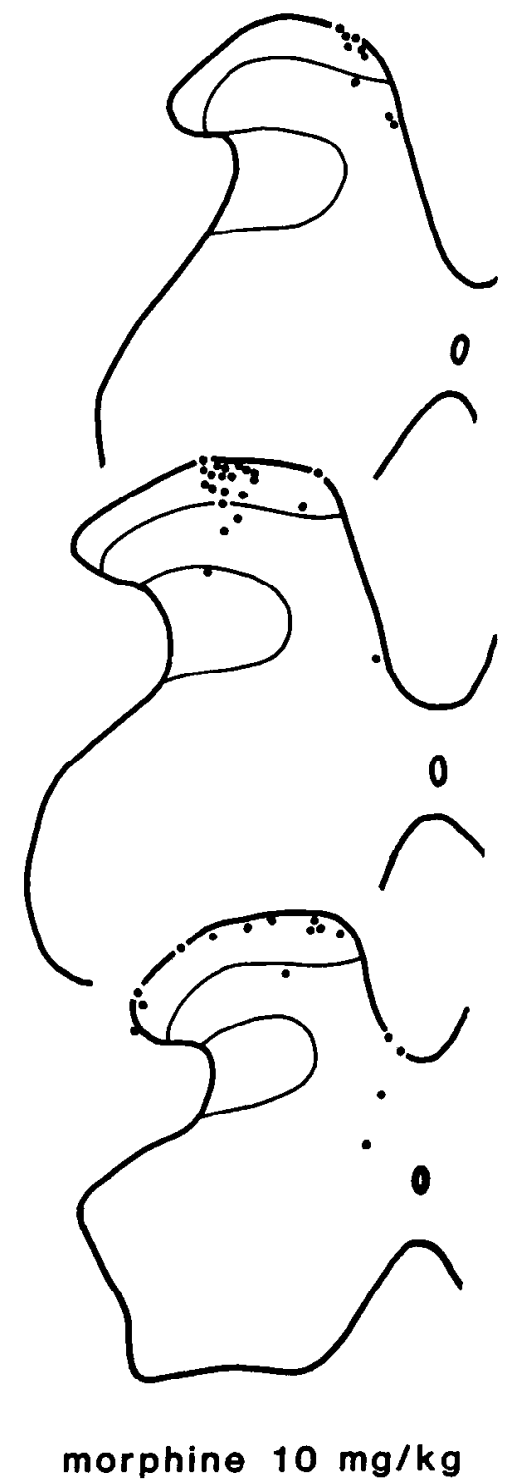

Figure 7. Camera lucida drawings showing the effect of morphine $(10 \mathrm{mg} /$ $\mathrm{kg}$ ) on FLI at the L3-L5 segmental levels $2 \mathrm{hr}$ after formalin injection. The rostrocaudal spread of Fos-immunoreactive neurons is also suppressed by morphine. At this dose, staining is not above control levels rostral or caudal to the segments shown.
1979; Molander and Grant, 1985; Sugiura et al. 1987). Since the majority of small-diameter myelinated and unmyelinated afferents terminate in the superficial dorsal horn (Light and Perl, 1979; Sugiura et al. 1987), it is reasonable to hypothesize that many of the neurons in the superficial dorsal horn which express the $c$-fos gene are driven monosynaptically by small-diameter, presumed nociceptive primary afferents from the injured paw.

Although Hunt et al. (1987) also demonstrated that noxious stimuli evoke FLI predominantly in laminae $\mathrm{I}_{1} \mathrm{II}_{\mathrm{o}}$, and $\mathrm{V}$, they did not report much labeling in the ventral horn. A significant difference in our 2 studies is that we examined noxious stimulusevoked FLI in awake, freely moving rats; Hunt et al. (1987) studied rats under chloral hydrate-barbiturate anesthesia. We do not believe that our results reflect a unique property of formalin as a tonic noxious stimulus; plantar injection of Freund's adjuvant, urate crystals injected around the ankle (Menétrey et al., 1989) or intraperitoneal injection of acetic acid (Presley et al., 1989) all evoke ventral horn $c$-fos activity in awake rats after a delay of several hours. In fact, we have systematically compared results in anesthetized and unanesthetized rats (Presley et al., unpublished observations) and found that noxious-stimulus evoked FLI in spinal cord neurons is suppressed by anesthetic drugs; this effect was most apparent on deeper dorsal horn and ventral horn neurons. Thus, noxious stimulus-evoked labeling of FLI in the deep dorsal horn and ventral horn of the spinal cord requires that a sustained noxious stimulus be administered, for at least $2 \mathrm{hr}$ in the case of the formalin test and that the stimulus be administered to an unanesthetized animal.

Whereas the contribution of neurons of the superficial laminae and of the neck of the dorsal horn to nociception is well established, the contribution of ventral neurons is less clear. Nociceptive, wide-dynamic-range neurons have been identified in the intermediate and ventromedial spinal gray matter (laminae VII and VIII) and around the central canal (lamina X) (Giesler et al., 1979; Menétrey et al., 1980; Molinari, 1982; Honda and Lee, 1984; Menétrey, 1987); many of these neurons contribute to ascending pathways, including the spinothalamic and spinoreticular tracts (Menétrey et al., 1980; Nahin et al., 1983; Menétrey, 1987; Ammons, 1987). These areas contain substantial numbers of noxious stimulus-evoked Fos-immunoreactive 


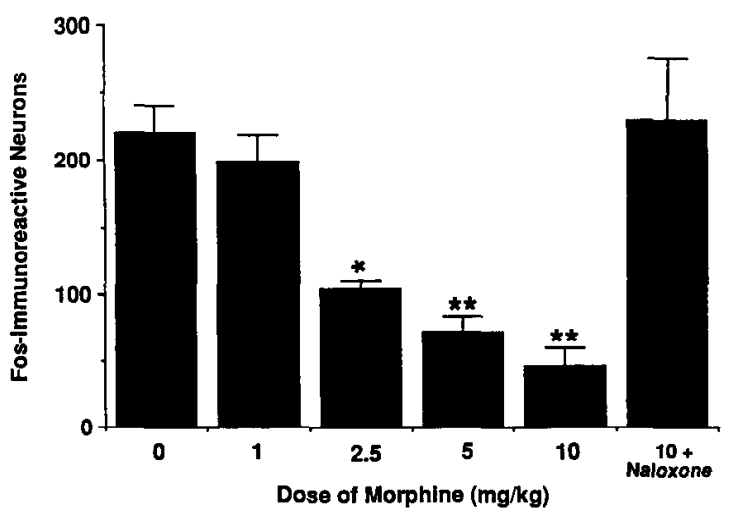

Figure 8. Quantification of the effect of subcutaneous morphine on the number of Fos-immunoreactive neurons evoked by formalin injection: morphine vs the total number of Fos-immunoreactive neurons (mean \pm SEM). There was a general downward trend in the numbers of positive cells with all doses of morphine; the effect was statistically significant after $2.5 \mathrm{mg} / \mathrm{kg}\left(47 \%\right.$ of control, $\left.{ }^{*} p<0.05\right), 5.0 \mathrm{mg} / \mathrm{kg}(33 \%$ of control, $\left.{ }^{* *} p<0.01\right)$, and $10 \mathrm{mg} / \mathrm{kg}\left(21 \%\right.$ of control, $\left.{ }^{* *} p<0.01\right)$. The effect of morphine $(10 \mathrm{mg} / \mathrm{kg})$ was completely abolished by the combined administration of naloxone $(2.0 \mathrm{mg} / \mathrm{kg})(105 \%$ of control, $p$ = NS).

neurons, some of which have been shown to project to the brain (Menétrey et al., 1989). Although there is a sparse projection of $\mathrm{A} \delta$ afferents to lamina $\mathrm{X}$, there is no direct projection of $\mathrm{C}$-fiber primary afferents onto laminae VII, VIII, or X (Light and Perl, 1979; Swett and Woolf, 1985; Sugiura et al., 1987). This suggests that the ventral horn Fos-immunoreactive neurons are activated polysynaptically; they may be driven directly by nociceptive neurons in laminae I and II (Light and Kavookian, 1988), or they may be excited indirectly, via nociresponsive spinobulbospinal loops involving the superficial dorsal horn (Giesler et al., 1981; Cervero and Wolstencroft, 1984). Importantly, nociceptive neurons in the ventral cord have large, complex, and often bilateral receptive fields, indicating that there is a considerable spatial convergence of input onto these cells. Our observation that deep dorsal horn and ventral horn Fos immunoreactivity has the greatest rostrocaudal distribution after formalin injection, often well outside of the known primary afferent segmental innervation of the injured paw, is consistent with these electrophysiological data.

The formalin stimulus also evoked Fos immunoreactivity in neurons of laminae III and IV, regions that predominantly contain cells only responsive to innocuous stimulation. Since Hunt et al. (1987) demonstrated that continuous nonnoxious stimulation evokes Fos staining in laminae III and IV, our initial assumption was that the Fos induction in these laminae derived from the vigorous licking and shaking of the paw that is produced by formalin injection in the awake rat. Morphine, of course, suppressed this behavior and reduced the expression of Fos in laminae III and IV. The reduction in Fos staining in laminae III and IV, however, was not statistically significant, which suggests that formalin injection also has a direct, morphine-insensitive, excitatory action on some large diameter primary afferent axons which input cells of laminae III and IV. In electrophysiological studies, however, Dickenson and Sullivan $(1987 \mathrm{a}, \mathrm{b})$ reported that formalin does not activate neurons which only respond to innocuous stimulation, the majority of which are found in laminae III and IV. Since the latter studies were performed in anesthetized rats, it is possible that the overall

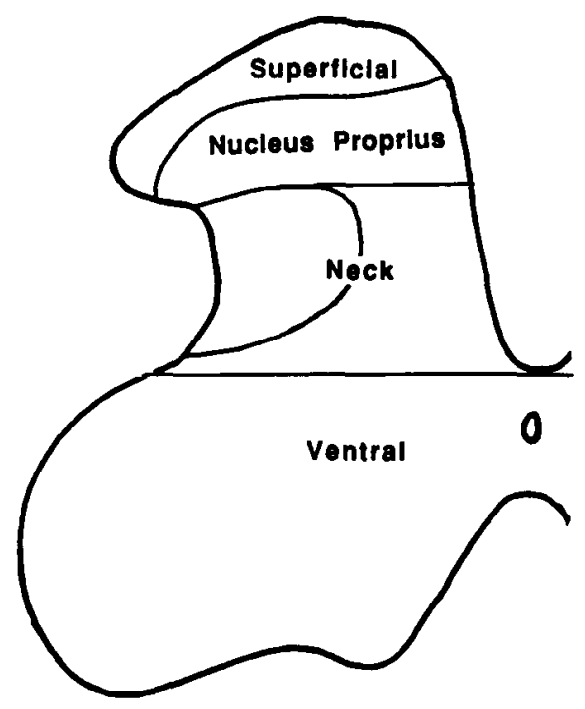

Figure 9. Camera lucida drawing of a hemisection of the spinal gray matter made under dark-field illumination showing specific regions that were analyzed for Fos immunoreactivity. The ventral border of the superficial dorsal horn (laminae I and II) and the boundary of the reticular part of the lamina $V$ were the most easily defined. Subsequently, the ventral border of the nucleus proprius (laminae III and IV) was defined by a line drawn tangentially across the dorsal part of lamina $\mathrm{V}$ to the medial border of the dorsal horn. The ventral border of the neck of the dorsal horn (laminae V and VI) was defined by a parallel line drawn from the ventral border of the dorsal columns to the lateral border of the dorsal horn. The remainder of the hemisection was defined as the ventral gray (laminae VII, VIII, IX and X).

reduction in activity was sufficient to have masked a direct formalin-evoked input to these neurons. We conclude, therefore, that the increased Fos immunoreactivity in neurons of laminae III and IV results from a combination of a formalin excitation of these neurons with the peripheral input that is secondary to the behavior produced by the nociceptive stimulus. Morphine would only suppress that latter component of the input to the lamina III and IV cells so that the overall reduction of Fos immunoreactivity may not be statistically significant.

\section{Modulation by systemic morphine}

Our observations on the regulation of Fos expression by morphine provide an important anatomical correlate of results from several previous studies that have demonstrated a dose-dependent, naloxone-reversible suppression of the formalin behavioral syndrome in rats by morphine and other opioid analgesics. Specifically, the latter experiments showed that although mild behavioral analgesia could be achieved with doses of systemic morphine as low as $1.0 \mathrm{mg} / \mathrm{kg}$ (Drower et al., 1987), most rats required doses in the $2.0-3.0 \mathrm{mg} / \mathrm{kg}$ range before significant analgesia was present (Dubuisson and Dennis, 1977; Dennis and Melzack, 1979, 1980; Abbott et al., 1982; Drower et al., 1987). Morphine in doses ranging from 5.0 to $10 \mathrm{mg} / \mathrm{kg}$ reliably produced a profound and long-lasting behavioral analgesia in the formalin test. Thus, our anatomical results paralleled these behavioral studies remarkably closely. We detected a reduction of Fos-immunoreactive neurons after morphine $(1.0 \mathrm{mg} / \mathrm{kg})$ and statistically significant suppression with doses of $2.5 \mathrm{mg} / \mathrm{kg}$ or greater.

Morphine can inhibit spinal nociceptors and produce analgesia directly via an action at the spinal cord (Yaksh, 1981) or, 


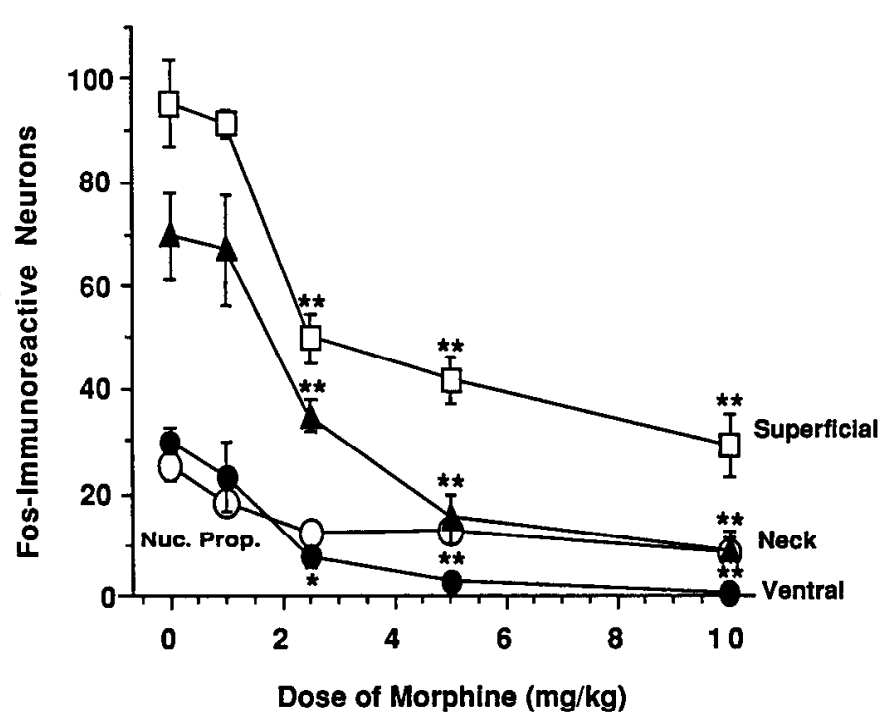

Figure 10. Morphine vs. the number of Fos-immunoreactive neurons in different laminar regions of the spinal gray matter (mean + SFM), including the superficial dorsal horn (laminae I and II), the nucleus proprius (laminae III and IV), the neck of the dorsal horn (laminae V and VI), and the ventral gray (laminae VII, VIII, and X). There was a statistically significant suppression of Fos-immunoreactive neurons after doses of morphine $2.5-10 \mathrm{mg} / \mathrm{kg}\left({ }^{*} p<0.05,{ }^{* *} p<0.01\right)$ in the superficial dorsal horn, in the neck of the dorsal horn, and in the ventral gray. The superficial dorsal horn consistently contained the greatest number of residual labeled cells; this was particularly evident at higher doses of morphine $(5.0$ and $10 \mathrm{mg} / \mathrm{kg}$ ). In contrast, labeling in the ventral gray was eliminated by these doses. The dose-response curve for the nucleus proprius was very flat, with no statistically significant suppression of labeling.

indirectly, via activation of brain-stem descending inhibitory control systems (Basbaum and Fields, 1984). In previous studies, using the paw-pinch (Basbaum et al., 1977) or tail flick test (Barton et al., 1980), we showed that bilateral lesions of the dorsolateral funiculi significantly reduce the analgesic action of up to $10 \mathrm{mg} / \mathrm{kg}$ systemic morphine. In fact, using the formalin test, we have preliminary data that lesions of the spinal cord significantly decrease the suppression of FLI produced by 5.0 $\mathrm{mg} / \mathrm{kg}$ of systemic morphine. To address the relative contribution of spinal versus supraspinal targets to the suppression of FLI, more specifically, we are presently studying the effects of selective spinal and supraspinal injection of morphine on noxious stimulus-evoked FLI in the spinal cord.

The majority of studies of the effects of morphine on spinal nociceptive processing have emphasized the regulation of neurons of the superficial dorsal horn and lamina V. In fact, opiate receptors are most densely distributed in the superficial dorsal horn and in lamina V (Lamotte et al., 1976; Atweh and Kuhar, 1977) and opioid peptides are found in high concentration in the same regions (Hökfelt et al., 1977; Glazer and Basbaum, 1981; Cruz and Basbaum, 1985); these regions are also the major target of raphe-spinal axons that are presumed to mediate opiate-activated descending bulbospinal controls (Basbaum et al., 1978; 1986; Basbaum and Fields, 1984). It was thus of particular interest that this was the area of greatest residual FLI after morphine treatment, even in doses sufficient to completely suppress the formalin behavioral syndrome. In fact, we found that at doses of 2.5 and $5.0 \mathrm{mg} / \mathrm{kg}$, there was a striking divergence of the slopes of suppression of FLI in the different laminae; this corresponds to the dose range where other investigators have

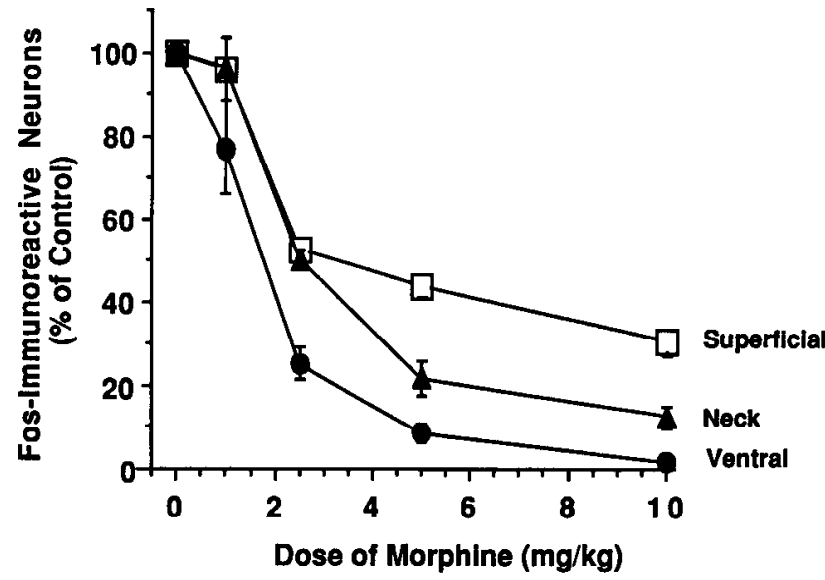

Figure 11. Effect of morphine on the number of Fos-immunoreactive neurons in different laminar regions expressed as a percentage of each region's own control (mean \pm SEM). Results from the nucleus proprius, which did not have significant suppression of FLI are not plotted here. The relative effect of morphine at doses of 1.0 and $2.5 \mathrm{mg} / \mathrm{kg}$ is identical in the superficial dorsal horn and in the neck of the dorsal horn. After $5.0 \mathrm{mg} / \mathrm{kg}$ morphine, the suppression of superficial FLI has plateaued, but there is a further deep decline in FLI in the neck of the dorsal horn. The effect of morphine is greatest on ventral FLI at all doses, with greater than $90 \%$ suppression in this area after $5.0 \mathrm{mg} / \mathrm{kg}$.

noted the onset of significant behavioral analgesia in the formalin test (Dubuisson and Dennis, 1977; Dennis and Melzack, 1979, 1980; Abbott et al., 1982; Drower et al., 1987). Specifically, above $5.0 \mathrm{mg} / \mathrm{kg}$, the numbers of Fos-immunoreactive neurons in the superficial laminae plateaued; those in the neck of the dorsal horn continued to decline steeply and the ventral FLI approached zero.

We were not able to take into account changes in staining intensity, i.e., neurons were categorized as labeled or unlabeled. Thus, the activity in a population of densely stained neurons in the control situation could be markedly suppressed by morphine, yet still have enough residual staining to be considered "labeled," and thus counted by our method of analysis. This could occur even if the absolute effect of morphine on the staining intensity of a densely labeled cell were greater than on a lightly labeled cell. The result might be an underestimate of the effect of morphine on neurons in the superficial dorsal horn, the area of most intense staining in both control and treatment groups. Our data indicate, however, that although analgesic doscs of morphine significantly reducc staining in ncurons of the superficial dorsal horn, abolition of activity in all superficial dorsal horn cells is not necessary for analgesia to be produced.

Since opiate receptors are not found in high concentrations in laminae VII and VIII (Lamotte et al., 1976; Atweh and Kuhar, 1977), it is likely that the effect of morphine on these neurons is indirect. As described above, the activity in these neurons may result from cascades of activily arising superficially or from supraspinal loops activated from the superficial dorsal horn. Conceivably, a morphine-induced reduction of activity in neurons of the superficial dorsal horn is sufficient to block the expression of Fos in the more ventral regions of the cord. This interpretation emphasizes the intimate interactions between neurons located in the dorsal horn and those located more ventrally.

Taken together, these observations suggest that analgesia from systemically administered opiates involves differential regula- 
tion of spinal nociceptive neurons; activity in subpopulations of spinal nociceptive neurons, and suppression of this activity by opiates, may contribute to different aspects of pain perception. The more restricted segmental distribution of superficial nociceptors is consistent with the view that these cells perform a more discriminative function that allows the animal to locate the noxious stimulus precisely, presumably to better organize an appropriate escape response. The cells in the ventral gray have a much more extensive spatial distribution, which would not promote precise localization of the stimulus but, rather, would signal the larger body part that had been injured. Activity in these neurons presumably underlies the more diffuse, persistent pain that follows significant tissue damage. The complete blockade of ventral nociceptive neurons by morphine, including the marked reduction in the rostral-caudal distribution of these cells, and the incomplete blockade of superficial cells are consistent with the preferential action of narcotics on the diffuse, rather than the discriminative aspects of pain. Of course, we cannot rule out the possibility that the residual staining in the superficial dorsal horn represents neuronal activity sufficient to permit recognition of the location of the noxious stimulus but insufficient to elicit the aversive properties of the stimulus which presumably contribute to the behavioral syndrome.

In conclusion, we have evoked neuronal expression of FLI in a model of tonic pain, the formalin test, and demonstrated a dose-dependent suppression of FLI with the standard narcotic analgesic, morphine. Importantly, the dose range for the modulation of neuronal Fos expression by morphine correlated well with the dose range previously described for behavioral analgesia produced by morphine in this test. Our data confirm the importance of neurons in the superficial dorsal horn and lamina $V$ to the processing of noxious stimuli in the awake rat, but they also emphasize the contribution of more ventral neurons in laminae VII, VIII, and X. The fact that analgesic doses of morphine had a particularly profound effect on Fos immunoreactivity in these latter regions suggests that blockade of activity in these regions is essential to produce clinical analgesia. Importantly, the absence of labeling of these ventral nociceptive neurons after treatment with anesthetics also highlights the problem of studying pain mechanisms in anesthetized animals; the information may be limited or substantially altered compared with the awake state. This is a particular problem in electrophysiological experiments, which, with few exceptions (Hoffman et al., 1981; Collins, 1987), are performed in decerebrate or anesthetized animals. The value of the electrophysiological approach to studying nociception is that the response properties of individual neurons can be characterized unequivocally. This approach, however, is limited because inferences about functional changes in populations of nociceptive neurons must be derived indirectly, after reconstruction of data from small numbers of cells in many animals. Thus, Fos immunocytochemistry provides a powerful adjunct to electrophysiological studies; it is possible to map large populations of functionally related neurons in individual animals which are physiologically intact and in which the behavior can be easily evoked and monitored in the unanesthetized state.

\section{References}

Abbott, F. V., R. Melzack, and C. Samuel (1982) Morphine analgesia in the tail-flick and formalin pain tests is mediated by different neural systems. Exp. Neurol. 75: 644-651.

Abram, S. E., and D. R. Kostreva (1986) Spinal cord metabolic re- sponse to noxious radiant heat stimulation of the cat hind footpad. Brain Res. 385: 143-147.

Alreja, M., P. Mutalik, U. Nayar, and S. K. Manchanda (1984) The formalin test: A tonic pain model in the primate. Pain 20:97-105.

Ammons, W. S. (1987) Characteristics of spinoreticular and spinothalamic neurons with renal input. J. Neurophysiol. 58: 480-495.

Atweh, S. F., and M. Kuhar (1977) Autoradiographic localization of opiate receptors in rat brain. I. Spinal cord and lower medulla. Brain Res. 124: 53-67.

Barton, C., A. I. Basbaum, and H. L. Fields (1980) Dissociation of supraspinal and spinal actions of morphine: A quantitative evaluation. Brain Res. 188: 487-498.

Basbaum, A. I., and H. L. Fields (1984) Endogenous pain control systems: Brainstem spinal pathways and endorphin circuitry. Annu. Rev. Neurosci. 7: 309-338.

Basbaum, A. I., D. D. Ralston, and H. J. Ralston III (1986) Bulbospinal projections in the primate: A light and electron microscopic study of a pain modulating system. J. Comp. Neurol. 250: 311-323.

Bashaum, A. I., N. J. Marley, J. O'Keefe, and C. H. Clanton (1977) Reversal of morphine and stimulus-produced analgesia by subtotal spinal cord lesions. Pain 3: 43-56.

Basbaum, A. I., C. H. Clanton, and H. L. Fields (1978) Three bulbospinal pathways from the rostral medulla of the cat: An autoradiographic study of pain modulating systems. J. Comp. Neurol. 178. 209-224.

Besson, J. M., and A. Chaouch (1987) Peripheral and spinal mechanisms of nociception. Physiol. Rev. 67: 67-186.

Calcagnetti, D. J., F. J. Helmstetter, and M. S. Fanselow (1988) Analgesia produced by centrally administered DAGO, DPDPE, and U50488H in the formalin test. Eur. J. Pharmacol. 153: 117-122.

Cervero, F., and J. H. Wolstencroft (1984) A positive feedback loop between spinal cord nociceptive pathways and antinociceptive areas of the cat's brainstem. Pain 20: 125-138.

Collins, J. G. (1987) A descriptive study of spinal dorsal horn neurons in the physiologically intact, awake, drug free cat. Brain Res. 416 : $34-42$.

Cruz, L., and A. I. Basbaum (1985) Multiple opioid peptides and the modulation of pain: Immunohistochemical analysis of dynorphin and enkephalin in the trigeminal nucleus caudalis and spinal cord of the cat. J. Comp. Neurol. 240: 331-348.

Curran, T. (1984) Viral and cellular fos proteins. Cell 36: 259-268.

Curran, T., and J. I. Morgan (1985) Superinduction of $c$-fos by nerve growth factor in the presence of peripherally active benzodiazepines. Science 229: 1265-1268.

Dennis, S. G., and R. Melzack (1979) Comparison of phasic and tonic pain in animals. In Advances in Pain Research and Therapy, Vol. 3 , J. I. Bonica et al., eds., pp. 747-760, Raven, New York.

Dennis, S. G., and R. Melzack (1980) Pain modulation by 5-hydroxytryptaminergic agents and morphine as measured by three pain tests. Exp. Neurol. 69: 260-270.

Dickenson, A. H., and A. F. Sullivan (1987a) Peripheral origins and central modulation of subcutaneous formalin-induced activity of rat dorsal horn neurones. Neurosci. Lett. 83: 207-211.

Dickenson, A. H., and A. F. Sullivan (1987b) Subcutaneous formalininduced activity of dorsal horn neurones in the rat: Differential response to an intrathecal opiate administered pre or post formalin. Pain 30: 349-360.

Drower, E. J., A. Stapelfield, R. A. Mueller, and D. L. Hammond (1987) The antinociceptive effects of prostaglandin antagonists in the rat. Eur. J. Pharmacol. 133: 249-256.

Dubuisson, D., and S. G. Dennis (1977) The formalin test: A quantitative study of the analgesic effects of morphine, meperidine, and brain stem stimulation in rats and cats. Pain 4: 161-174.

Giesler, G. J., D. Menétrey, and A. I. Basbaum (1979) Differential origins of spinothalamic tract projections to medial and lateral thalamus in the rat. J. Comp. Neurol. 184: 107-126.

Giesler, G. J., R. P. Yezierski, K. D. Gerhart, and W. D. Willis (1981) Spinothalamic tract neurons that project to medial and/or lateral thalamic nuclei: Evidence for a physiologically novel population of spinal cord neurons. J. Neurophysiol. 46: 1285-1308.

Glazer, E. J., and A. I. Basbaum (1981) Immunohistochemical localization of leucine-enkephalin in the spinal cord of the rat: Enkephalincontaining marginal neurons and pain modulation. J. Comp. Neurol. 196: 377-389.

Greenberg, M. E., E. B. Ziff, and L. A. Greene (1986) Stimulation of 
neuronal acetylcholine receptors induces rapid gene transcription. Science 234: 80-83.

Hökfelt, T., A. Ljungdahl, L. Terenius, R. Elde, and G. Nilsson (1977) Immunohistochemical analysis of peptide pathways possibly related to pain and analgesia. Proc. Natl. Acad. Sci. USA 74: 3081-3085.

Hoffman, D. S., R. Dubner, R. L. Hayes, and T. P. Medlin (1981) Neuronal activity in medullary dorsal horn of awake monkeys trained in a thermal discrimination task. I. Responses to innocuous and noxious thermal stimuli. J. Neurophysiol. 46: 409-427.

Honda, C. N., and C. L. Lee (1984) Immunohistochemistry of synaptic input and functional characterization of neurons near the spinal central canal. Brain Res. 343: 120-128.

Hsu, S. M., L. Raine, and H. Fanger (1981) Use of avidin-biotinperoxidase complex $(\mathrm{ABC})$ in immunoperoxidase techniques: A comparison between $\mathrm{ABC}$ and unlabelled antibody (PAP) procedures. J. Histochem. Cytochem. 29: 577-580.

Hunskaar, S., O. Berge, and K. Hole (1986) Dissociation between antinociceptive and anti-inflammatory effects of acetylsalicylic acid and indomethacin in the formalin test. Pain 25: 125-132.

Hunt, S. P., A. Pini, and G. Evan (1987) Induction of $c$-fos-like protein in spinal cord neurons following sensory stimulation. Nature 328: 632-634

Lamotte, C., C. B. Pert, and S. H. Snyder (1976) Opiate receptor binding in primate spinal cord: Distribution and changes after dorsal root section. Brain Res. 112: 407-412.

Light, A. R., and E. R. Perl (1979) Spinal termination of functionally identified primary afferent neurons with slowly conducting myelinated fibers. J. Comp. Neurol. 186: 133-150.

Light, A. R., and A. M. Kavookian (1988) Morphology and ultrastructure of physiologically identified substantia gelatinosa (lamina II) neurons with axons that terminate in deeper dorsal horn laminae (III-V). J. Comp. Neurol. 267: 172-189.

Menétrey, D. (1987) Spinal nociceptive neurons at the origin of long ascending pathways in the rat: Electrophysiological, anatomical and histochemical approaches. In Thalamus and Pain, J. M. Besson et al., eds., pp. 21-34. Elsevier, Amsterdam.

Menétrey, D., A. Chaouch, and J. M. Besson (1980) Location and properties of dorsal horn neurons at the origin of the spinoreticular tract in lumbar cnlargement of the rat. J. Neurophysiol. 44: 862-877.

Menétrey, D., A. Gannon, J. D. Levine, and A. I. Basbaum (1989) The expression of $c$-fos protein in presumed-nociceptive interneurons and projection neurons of the rat spinal cord: Anatomical mapping of the central effects of noxious somatic, articular and visceral stimulation. J. Comp. Neurol. (in press).

Molander, C., and G. Grant (1985) Cutaneous projections from the rat hindlimb foot to the substantia gelatinosa of the spinal cord studied by transganglionic transport of WGA-HRP conjugate. J. Comp. Neurol. 237: 476-84.

Molander, C., Q. Xu, and G. Grant (1984) The cytoarchitechtonic organization of the spinal cord in the rat. I. The lower thoracic and lumbosacral cord. J. Comp. Neurol. 230: 133-141.

Molinari, H. H. (1982) The cutaneous sensitivity of units in laminae VII and VIII of the cat. Brain Res. 234: 165-169.

Morgan, J. I., and T. Curran (1986) Role of ion flux in the control of $c$-fos expression. Nature 322: 552-555.

Morgan, J. I., D. R. Cohen, J. L. Hempstead, and T. Curran (1987) Mapping patterns of $c-f o s$ expression in the central nervous system after seizure. Science 237: 192-196.

Nahin, R. L., A. M. Madsen, and G. J. Giesler (1983) Anatomical and physiological studies of the gray matter surrounding the spinal cord central canal. J. Comp. Neurol. 220: 321-335.

Presley, R. W., D. L. Hammond, K. R. Gogas, J. D. Levine, and A. I Basbaum (1989) Morphine and U50488H suppress noxious visceral stimulation-evoked Fos protein immunoreactivity in the spinal cord and nucleus of the solitary tract (NTS) of the rat. Soc. Neurosci. Abstr. (in press)

Sambucetti, L. C., and T. Curran (1986) The Fos protein complex is associated with DNA in isolated nuclei and binds to DNA cellulose. Science 234: 1417-1419.

Sagar, S. M., F. R. Sharp, and T. Curran (1988) Expression of c-fos protein in brain: Metabolic mapping at the cellular level. Science 240 : $1328-1331$

Sugiura, Y., C. L. Lee, and E. R. Perl (1987) Central projections of identified, unmyelinated $(\mathrm{C})$ afferent fibers innervating mammalian skin. Science 234: 358-361.

Swett, J. E., and C. J. Woolf (1985) The somatotopic organization of primary afferent terminals in the superficial laminae of the dorsal horn of the rat spinal cord. J. Comp. Neurol. 231: 66-77.

Wong-Riley, M. T., and G. H. Kageyama (1986) Localization of cytochrome oxidase in the mammalian spinal cord and dorsal root ganglia with quantitative analysis of ventral horn cells in monkeys. J. Comp. Neurol. 245: 41-61.

Yaksh, T. L. (1981) Spinal opiate analgesia. Characteristics and principles of action. Pain 11: 293-346. 